\title{
Spatiotemporal distribution of seasonal bird assemblages on land-bridge islands: linking dynamic and static views of metacommunities
}

Chuanwu Chen ${ }^{1,2} \mathbb{0}$, Marcel Holyoak ${ }^{3}$, Yanping Wang ${ }^{1,2}$, Xingfeng $\mathrm{Si}^{4}$ and Ping Ding ${ }^{1 *}$

\begin{abstract}
Background: Although assessing temporal dynamics of populations is crucial for understanding metacommunities, empirical studies have primarily analyzed only static snapshots of communities. Here, we present a holistic view of how species traits and habitat characteristics relate to metacommunity dynamics and use it to test for differences in the spatiotemporal distribution of seasonal bird assemblages.

Methods: We surveyed forest birds in breeding and winter seasons within 36 islands for 9 years. We then grouped birds into four landbird assemblages, selected on the basis of published differences in biology or ecology: winter residents, migratory winter visitors, breeding summer residents, and migratory summer visitors. We estimated dynamic species colonization and extirpation through the 9-year period, and evaluated the associations among island attributes, species attributes and community composition.

Results: Overall, winter and summer residents showed strong associations between composition and habitat structure of the islands. In addition, winter and summer residents on large islands had lower extirpation and turnover than winter and summer visitors. Visitor assemblages showed no significant habitat associations, and in winter had high extirpation rates and small body sizes. By contrast, local extirpation of summer visitors was correlated with local species richness, indicating a likely effect of competition on extirpation.

Conclusions: Our results demonstrated repeated patterns among species composition, bird traits, habitat/island characteristics and observed metacommunity dynamics. Winter and summer residents best matched species sorting and patch dynamics, respectively, due to differences in resource availability and requirements of overwinter survival versus breeding. Summer visitors were consistent with species sorting and winter visitors were randomly distributed, likely because of interactions with resident competitors. Our results highlight that coexisting seasonal migrant and resident assemblages differ in their spatial dynamics, with consequences for relevant conservation and management strategies.
\end{abstract}

Keywords: Body size, Colonization, Competition, Extirpation, Island turnover, Metacommunity

\section{Background}

The metacommunity concept, which unifies spatial and community ecology, is an important theoretical advance in recent years (Leibold et al. 2004; Holyoak et al. 2005). Metacommunity theory emphasizes extinction-colonization dynamics and species traits such as dispersal and

\footnotetext{
${ }^{*}$ Correspondence: dingping@zju.edu.cn

${ }^{1}$ College of Life Sciences, Zhejiang University, Hangzhou 310020, China

Full list of author information is available at the end of the article
}

niche requirements in determining community composition (Leibold et al. 2004). Much research has used such information to make inferences about the relevance of idealized metacommunity paradigms and to help interpret life-history strategies of species and trade-offs that are expected to contribute to their co-existence (Logue et al. 2011). However, published metacommunity studies have seldom explicitly included temporal dynamics (Brown et al. 2017), and only a few have presented a 
holistic view of how species traits and habitat characteristics relate to metacommunity structure (Pavoine et al. 2014).

Four idealized paradigms are generally identified for metacommunities, representing the temporal and spatial dynamics of communities. Species sorting emphasizes environmental gradients (or habitat or patch types) causing species to have habitat-specific demography. In such a system, species are regulated by traits related to habitat-related niches, and dispersal is not sufficient to alter their distribution (Logue et al. 2011). Consequently, communities will reach equilibrium with low extirpation and turnover (Leibold et al. 2004). Mass effects assume that habitat-specific demography (e.g. along environmental gradients) and dispersal both affect species richness and composition (Leibold et al. 2004). Mass effects cause populations to be present in both source and sink habitats, and a spillover of species among populations makes composition depending on dispersal ability or patch connectivity. Irrespective of the rates of immigration and emigration, mass or rescue effects will result in low turnover of populations in spatial niches (Brown and KodricBrown 1977). Patch dynamics assume that patches are identical and that species richness and composition are determined by species competitive ability and colonization ability (Leibold et al. 2004). Therefore, extirpation, colonization and turnover are expected to be frequent under such a system (e.g. Amarasekare et al. 2004; Ellis et al. 2006). Finally, neutral dynamics assume that all individuals of all species are identical in their competitive ability, movement and habitat requirement (Hubbell 2001). Neutral dynamics would be reflected by weak associations between community composition, species traits and environmental characteristics, and create high extirpation, colonization and turnover (Chave 2004).

The above four paradigms are either based on or produce expectations of differences in extirpation, colonization, turnover and habitat (or patch) associations of either these dynamics or community composition (Table 1). However, as suggested by Brown et al. (2017), empirical studies of metacommunities have primarily analyzed only snapshots of community composition. Such static studies reach their limits in trying to apply a single idealized metacommunity type to whole metacommunities, as well as not investigating the associations between traits and species distributions (e.g. Brown et al. 2017; Leibold and Chase 2017). In fact, associations between traits and habitats are likely to go beyond the simple view of species sorting (Leibold et al. 2004), because different habitats are likely to have different traits that are selected for in them. For instance, many animalivorous bat species rarely persisted in small fragments (Farneda et al. 2015) and highly-mobile butterflies were strongly dependent on landscape composition (Barbaro and van Halder 2009). Additionally, different assemblages or guilds may occur in the same habitats but have different dynamics. For instance, seasonally migratory birds were more sensitive to loss due to fragmentation than non-migratory ones (Barbaro and van Halder 2009; Chen et al. 2018a). Here we use multivariate RLQ and fourth-corner analyses, which test and estimate trait-environment relationships, along with tests related to island biogeography theory to study metacommunity dynamics of seasonal and migratory versus resident land-bird assemblages.

We can draw predictions of what differences to expect among the temporal dynamics of land-bird assemblages from existing biogeographical and metacommunity studies (Murgui 2007; Stracey and Pimm 2009), and known biology and ecology of community members. Resident species are non-migratory species in a certain region (notwithstanding partial migration; Schoener 1968; Herrera 1978), whereas seasonal visitors (or migrants) may leave during unfavorable seasons (Herrera 1978; Hutto 1985; Klingbeil and Willig 2016). Since resident bird species generally have different requirements (overwinter survival vs. breeding) in breeding (summer) and winter

Table 1 Summary of our predictions for associations between metacommunity paradigms, species functional traits, and species extirpation, colonization as well as turnover rates for winter residents $\left(W_{R}\right)$, winter visitors $\left(W_{V}\right)$, summer residents $\left(S_{R}\right)$ and summer visitors $\left(S_{v}\right)$ in the Thousand Island Lake, China

\begin{tabular}{|c|c|c|c|c|c|c|}
\hline \multirow[t]{2}{*}{ Predictions } & \multicolumn{3}{|l|}{ Temporal dynamics } & \multicolumn{2}{|c|}{ Functional associations } & \multirow[t]{2}{*}{ Confirmed } \\
\hline & Extirpation rate & Colonization rate & Turnover rate & Dispersal ability & Habitat specificity & \\
\hline $\mathrm{S}_{\mathrm{R}}$ and $\mathrm{S}_{\mathrm{V}}$ & Low (supported) & $\begin{array}{l}\text { Low to medium (sup- } \\
\text { ported) }\end{array}$ & Low (supported) & $\begin{array}{l}\text { Low to medium (not } \\
\text { specific) }\end{array}$ & Strong (supported) & Species sorting \\
\hline$W_{R}$ or $W_{V}$ & High (supported) & $\begin{array}{l}\text { Medium to high (sup- } \\
\text { ported) }\end{array}$ & High (supported) & $\begin{array}{l}\text { Medium to high (not } \\
\text { specific) }\end{array}$ & Weak (partly supported) & Patch dynamics \\
\hline$W_{v}$ & Random (supported) & Random (supported) & High (supported) & $\begin{array}{l}\text { Low to medium (sup- } \\
\text { ported) }\end{array}$ & None (supported) & Neutral dynamics \\
\hline / & Low & High & Low & High & Strong & Mass effects \\
\hline
\end{tabular}


seasons (Chen et al. 2018a), we treated resident species as summer residents and winter residents separately. In specific, summer residents are central-place foragers (Schoener 1968) with active territorial defense, which limits their movements and makes them strongly dependent on habitat characteristics for all required resources (Levey and Stiles 1992; White and Hurlbert 2010; Özkan et al. 2013). Therefore, this may reduce their temporal extirpation through species' segregation into separate niches, restrict species colonization by movement limitation, and overall promote species sorting in residents when breeding. By comparison, severe winter weather and food shortage are expected to create high mortality and extirpation of wintering birds (Wiens 1992; Murcia 1995; Nour et al. 2010), or wintering birds may compensate for limited winter resources by being highly mobile (Wiens 1992; Murgui 2007, 2010; Fattorini 2010). Most likely, we expect high local extirpation and colonization for winter residents, leading to patch or neutral dynamics. Extirpation may be replaced by a temporary evacuation if bird species are sufficiently mobile (Brook and Buettel 2016).

By contrast, seasonal visitors and residents often differ in their habitat and resource requirements (Zuckerberg et al. 2016). Resident species are often viewed as being structured by habitat associations and interspecific interactions (Klingbeil and Willig 2016), whereas visitors are more generalized in foraging, habitat use, and morphological traits (Herrera 1978). Moreover, seasonal visitors also need to compete with resident species when they arrive at new habitats (e.g. Klingbeil and Willig 2016), and are usually characterized as being competitively inferior (Leck 1972; Tramer 1974; Herrera 1978). For instance, studies showed that, to avoid competition with resident species, winter visitors fill vacant niches unoccupied by resident species (Herrera 1978), settle randomly and lack ties to specific habitats (Leisler 1992). Weak competitive ability of visitors could either prevent them from colonizing because of priority effects exerted by residents (Fukami 2015; Klingbeil and Willig 2016), or cause competitive exclusion. High mobility of winter visitor species relative to residents and weak habitat associations should create either patch or neutral dynamics. By contrast, we predict that summer visitors might be expected to correspond to species sorting because of their strong habitat requirements and low mobility during breeding.

Here, we sampled bird assemblages of winter residents, summer residents, winter visitors and summer visitors on 36 islands in a large inundated lake, and examined the relationships between metacommunity dynamics, functional traits and island characteristics. Specifically, we tested the following four hypotheses: (1) Extirpation (or evacuation) rates will be higher for winter residents and winter visitors than summer residents and summer visitors, and highest of all for winter visitors. This is expected because of strong associations with habitats for breeding birds and high mobility of winter visitors. (2) Winter residents and winter visitors will have higher colonization rates in this region compared to summer residents and summer visitors, due to their high dispersal ability and weak territory associations. Related to this, habitat associations will be lower for winter birds than summer birds. (3) From (1) and (2), it follows that the overall turnover of bird assemblages is expected to be higher for winter than summer bird assemblages. An alternative is that turnover would be low if extirpation and colonization occur repeatedly in certain species (Beven 1976) and cancel each other out. (4) Summer residents and summer visitors will show stronger associations between species composition and habitat or island variables (and species characteristics associated with habitat specificity) than residents and winter visitors. This is because of the high habitat specificity expected for breeding birds. Overall, the expected net effect of the above is that we expect different metacommunity dynamics for winter versus summer residents, winter versus summer visitors, and resident versus migratory assemblages.

\section{Methods \\ The study system}

The Thousand Island Lake (hereafter TIL, $29^{\circ} 22^{\prime}-$ $29^{\circ} 50^{\prime} \mathrm{N}, 118^{\circ} 34^{\prime}-119^{\circ} 15^{\prime} \mathrm{E}$ ) was formed in 1959 by damming of the Xin'anjiang River in Zhejiang Province, China (Fig. 1). The lake has 1078 islands and covers an area of $573 \mathrm{~km}^{2}$ when the water reaches its highest level $(108 \mathrm{~m}$; Wang et al. 2010). The area is mainly covered by secondary pine (Pinus massoniana) forest, with many broadleaved trees and shrubs. The climate consists of hot and wet summers and cold windy winters, with average daily temperatures of $6.4{ }^{\circ} \mathrm{C}$ in winter and $30.9^{\circ} \mathrm{C}$ in summer (Si et al. 2014). The area is seasonal in weather conditions and resource supply, with many trees being winter-deciduous and most plant growth ceasing during winter (Chen et al. 2018a).

\section{Data collection}

We surveyed bird communities on 36 islands and two nearby mainland sites (M1 and M2) during nine breeding (April-June, 2007-2015) and nine winter seasons (November-January, 2007-2016) (Fig. 1). Island area $(A, \mathrm{ha})$ spanned with variation from 0.57 to 1300 ha $(50.1 \pm 217.9$ ha, mean $\pm S D)$, and straight-line distance to the nearest mainland $(D I, \mathrm{~m})$ was $20 \mathrm{~m}$ to over $3.71 \mathrm{~km}$ (Additional file 1: Table S1; Chen et al. 2018b). We were 


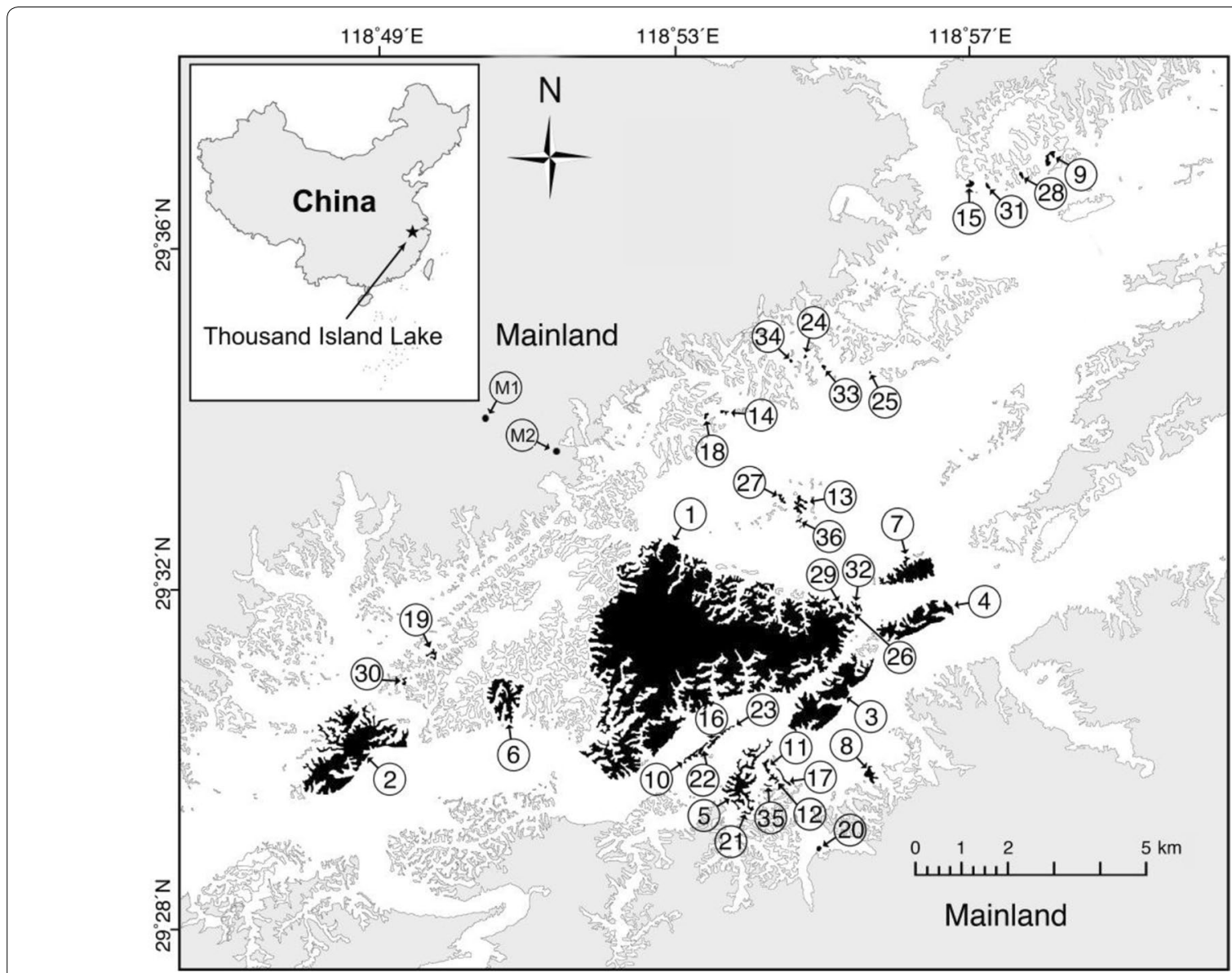

Fig. 1 Map of the 36 study islands in the Thousand Island Lake, China. Islands are numbered in order of decreasing area and number 1 represents the largest island

concerned that distance-based isolation would miss potential influences of islands on each other, so we also considered the influence of neighboring islands by estimating the buffer-based isolation $(B I)$. This was measured as the area of $2-\mathrm{km}$ region around a focal island (connectivity), and afterward calculated their complements (1 connectivity) to make isolations largely independent of island sizes (Song et al. 2018). Results based on both isolation measures were largely identical, so here we use the simpler measure BI in priority (Song et al. 2018). Sampling effort on each island was proportional to the logarithm of island area (Schoereder et al. 2004; Song et al. 2018). Other details of sampling and the justification for its adequacy are given in Additional file 2: Appendix. We used the number of distinct habitat types per island to measure habitat richness, and included seven habitat types identified by Wang et al. (2010): coniferous forest, broad leaved forest, mixed coniferous broad leaved forests, bamboo groves, shrubs, grassland, and farmland.

\section{Bird surveys}

Island bird communities were sampled using line transects (Bibby et al. 2000), and on days without rainfall, strong wind or high temperature (Wang et al. 2011). Additional details of census methods and definitions of wintering and breeding are given in Additional file 2: Appendix. In total, each transect was visited a total of 234 times across the study period, with at least nine visits per season (Song et al. 2018). We considered only terrestrial birds, and excluded raptors (large territories), water birds, passage migrants, and species that flew over islands (Wang et al. 2011). Species with only one record across the whole study period were also excluded because they were not clearly regular assemblage members. Records on islands were converted to a presence-and-absence species occupancy matrix for each season. We then calculated occupancy frequency for each species as the sum of presences of this species through the 9 years (Additional file 1: Table S2). We also surveyed the bird richness 
of two mainland sites (M1 and M2; Fig. 1), using the same sampling methods (Si et al. 2017).

\section{Species characteristics}

Species were assigned to four bird assemblage types due to differences in resource availability and requirements of overwinter survival versus breeding: winter residents $\left(\mathrm{W}_{\mathrm{R}}\right)$, winter visitors $\left(\mathrm{W}_{\mathrm{V}}\right)$, summer residents $\left(S_{R}\right)$ and summer visitors $\left(S_{V}\right)$. The resident species that we sampled during breeding seasons (April-June) were defined as summer residents, and those present in nonbreeding seasons (November-January) were winter residents (Chen et al. 2018a). Winter and summer visitors were migratory species that visited the islands during November-January surveys and April-June surveys, respectively.

Two habitat-associated traits (vertical and habitat specificity), one dispersal-associated trait (movement capacity) and body mass (linked to both habitat and dispersal) were chosen as predictors to test for correlations with species occupancy frequency (Additional file 1: Table S3). Body mass (g) was measured as the mean body mass of multiple adult individuals. Movement capacity was an index of each species' mobility, and calculated as mean wing length $(\mathrm{mm}) /$ cube-root of body mass (Fischer and Lindenmayer 2005; Wang et al. 2015). Vertical specificity was quantified as ground (score 1), understory (2), midstory (3), and canopy (4) for each bird species. Habitat specificity was the number of habitats used by a given species, ranging from 1 to 7 (Wang et al. 2010, 2015).

We log-transformed body mass and movement capacity to normalize their distributions. Information of migratory status, body mass, movement capacity, vertical and habitat specificity was derived from the literature (Zhuge 1990; MacKinnon et al. 2000) and our field observations.

\section{Extirpation, colonization and turnover rates}

We calculated extirpation, colonization and turnover rates separately for each bird assemblage following Russell et al. (2006) (detailed in Additional file 2: Appendix): (1) Colonization rate, $\lambda$, is the probability of a species absence on an island $i$ in year $t$ but presence in the second year $t+1$. (2) Extirpation rate, $\mu$, is the probability of a species being present on an island in year $t$ followed by its absence in year $t+1$. (3) Observed extirpation rate, $\delta$, is the probability of a species totally going extinct after its presence in year $t$ and not be rescued by colonization of new individuals in year $t+1$. So, $\delta=\mu \times(1-\lambda)$. (4) Temporal turnover is the number of species that changes through either colonization or extirpation in two consecutive years on an island, divided by their total numbers in both years. (5) Overall incidence represents estimated species richness as a proportion of total species richness (pool includes the mainland; Additional file 2: Appendix) for each island in a given year. All of these variables represent estimated probabilities because the method allows multiple extirpation and colonization events occurring between years. Here, we shall note that the concepts of colonization and extirpation used in this study may differ from their original meanings in the Theory of Island Biogeography, mainly because of poor isolation of the study region and the comparative high dispersal ability of bird species.

In two consecutive years, the presence $(\mathrm{P})$ and absence (A) of one species on each island can yield four transitions: AA, AP, PA and PP, which correspond with $1-\lambda, \lambda, \delta$ and $1-\delta$, respectively (Russell et al. 2006). We then estimate the extirpation, colonization and turnover rates through 9-year period in three steps. First, we included area $(A)$ and isolation $(B I)$ in multivariate logistic regressions to model each transition. Because these transitions are nonindependent, we used maximum likelihood estimation to model all four transitions simultaneously, which was calculated as $L=\prod_{i}\left(1-\lambda_{i}\right)^{A A_{i}} \lambda_{i}^{A P_{i}} \delta_{i}^{P A_{i}}\left(1-\delta_{i}\right)^{P P_{i}}$. Second, we used Akaike's information criterion (AIC) for model selection, and calculated the importance of area and isolation by summing weight $\left(w_{i}\right)$ to account for model selection uncertainty and possibly imperfect detection (Burnham and Anderson 2003; MacKenzie et al. 2009). Finally, we estimated model-averaged values, with approximately $\pm 95 \%$ confidence intervals on the logic scale (as $\pm 2 \mathrm{SE}$ ). We then calculated the $w_{i}$-weighted averages of the predictions across all candidate models to predict colonization, extirpation, turnover rates and incidence for each island (Russell et al. 2006).

To test our first three hypotheses, we analyzed the correlations between extirpation, colonization and turnover with area or isolation, and then applied ANOVA and Tukey's HSD tests to compare average extirpation and colonization rates among bird assemblages (Hypotheses 1, 2 and 3). Moreover, seasonal visitors may also compete with residents for territories or resources in each season. To indicate a likely competitive ability of species, we tested the correlations between extirpation and species incidence or distribution of body size for each bird assemblage. Averaged body mass per island $\left(S_{\text {ave }}\right)$ was $S_{\text {ave }}=\sum\left(S_{i} O_{i}\right) / \sum O_{i}$, where $S_{i}$ is the body mass of species $i$, and $O_{i}$ is the occupancy frequency of species $i$ on each island. All of above analyses were carried out in $R(R$ Core Team 2018).

\section{RLQ and fourth-corner analyses}

We used RLQ analysis (Dolédec et al. 1996) to test whether the covariance between island characteristics (table R) and species traits (table Q) was related to the 
occupancy frequency of each bird assemblage (table L). RLQ is a three-table ordination method, allowing a direct ordination of species functional traits according to variables describing patch (or island) characteristics (Dolédec et al. 1996; Dray et al. 2014). By combining these three tables, RLQ analysis was used to test the correlation between environmental variables and species traits (Dray et al. 2014). Table $Q$ included four species traits (body size, movement capacity, vertical and habitat specificity), and table $\mathrm{R}$ included four island variables $(A, B I, D I$ and habitat richness).

We used fourth-corner analysis (Legendre et al. 1997) to further test the relationships between island characteristics (table R) and species ecological traits (table Q) with species $\mathrm{L}$ table. The fourth-corner test was performed using two null models (Dray et al. 2014): Model 2 tests whether island characteristics have no influence on species occurrences with fixed traits (i.e. no relationship between $R$ and $L$ ); Model 4 considers no relationship between $\mathrm{L}$ and $\mathrm{Q}$, which tests whether species traits have no influence on species occurrences with fixed island characteristics (Dray et al. 2014). We assessed the significance in fourth-corner analyses based on 49,999 permutations, and performed all analyses separately for each bird assemblage using R-package ade4 (Dray and Dufour 2007).

To test our Hypothesis 4, we used habitat associations as indicators of species sorting or mass effects, and movement capacity as indicative of patch dynamics or mass effects. No significant association between species trait and occurrence would indicate neutral dynamics.

\section{Results}

\section{Extirpation, colonization and turnover rates}

A total of 56 winter residents $(22 \pm 8$, mean \pm SD), 24 winter visitors $(9 \pm 3,29), 56$ summer residents $(25 \pm 5$, $67)$ and 17 summer visitors $(4 \pm 2,19)$ were detected more than once on the 36 islands. For all bird assemblages, island area was a stronger predictor of both colonization and extirpation rates than isolation in models with $\triangle \mathrm{AIC}<2$ (Table 2; Additional file 2: Table S4). By contrast model-averaged effects for each assemblage for isolation overlapped zero (Table 2), and we therefore do not further report them.

As predicted by Hypotheses 1 and 3, average extirpation and island turnover rates were higher for winter visitors than for winter or summer residents, and lowest for summer visitors (Fig. 2d, f). By contrast, the colonization rates of summer and winter residents were significantly higher than those of summer and winter visitors, which is inconsistent with Hypothesis 2 (Fig. 2b). The incidence of winter and summer visitors was also lower
Table 2 Importance and weighted average parameter estimate for island area and isolation as predictors of colonization and extirpation rates for winter residents $\left(W_{R}\right)$, winter visitors $\left(W_{V}\right)$, summer residents $\left(S_{R}\right)$ and summer visitors $\left(S_{\mathrm{V}}\right)$

\begin{tabular}{|c|c|c|c|c|}
\hline & \multicolumn{2}{|c|}{ Colonization rate } & \multicolumn{2}{|c|}{ Extirpation rate } \\
\hline & Importance & $a$ & Importance & $\beta$ \\
\hline \multicolumn{5}{|l|}{$W_{R}$} \\
\hline Area & 1.00 & $0.22 \pm 0.03^{*}$ & 1.00 & $-0.13 \pm 0.04^{*}$ \\
\hline Isolation & 0.27 & $-0.07 \pm 0.64$ & 0.27 & $-0.05 \pm 0.95$ \\
\hline \multicolumn{5}{|l|}{$W_{v}$} \\
\hline Area & 1.00 & $0.12 \pm 0.05^{*}$ & 1.00 & $-0.11 \pm 0.06^{*}$ \\
\hline Isolation & 0.37 & $0.52 \pm 1.04$ & 0.27 & $0.06 \pm 1.39$ \\
\hline \multicolumn{5}{|l|}{$S_{R}$} \\
\hline Area & 1.00 & $0.12 \pm 0.03^{*}$ & 1.00 & $-0.17 \pm 0.04^{*}$ \\
\hline Isolation & 0.29 & $-0.13 \pm 0.60$ & 0.63 & $0.67 \pm 0.74$ \\
\hline \multicolumn{5}{|l|}{$S_{V}$} \\
\hline Area & 1.00 & $0.21 \pm 0.08^{*}$ & 0.73 & $0.09 \pm 0.09^{*}$ \\
\hline Isolation & 0.40 & $1.00 \pm 1.78$ & 0.29 & $0.49 \pm 2.26$ \\
\hline
\end{tabular}

Values are averages $\pm 95 \%$ confidence interval. An asterisk $\left(^{*}\right)$ indicates that the $95 \%$ confidence interval of the weighted parameter estimate excludes zero

than winter and summer residents (Fig. $2 g$, h), which presumably limited their colonization rates compared to resident assemblages (Fig. 2a, b). Hypothesis 2 correctly predicted that winter residents had higher colonization rates than summer residents, except on the smallest islands (Fig. 2a).

All bird assemblage types showed strong correlations between the selected four variables and island area (Fig. 2 left column), but with substantial differences among assemblages. On larger islands, winter residents, winter visitors, and summer residents showed lower extirpation and island turnover rates and higher colonization (Fig. 2 left column). By contrast, extirpation and island turnover rates were higher on larger islands than smaller ones for summer visitors (Fig. 2c, e).

For summer visitors, extirpation rate increased with incidence (Fig. 3a), suggesting either increasing negative species interactions or a loss of rescue effects with increasing incidence. By contrast, winter visitors, winter residents and summer residents showed a decline in extirpation with increasing incidence (Fig. 3a). Extirpation rates were correlated with average bird body mass per island (Fig. 3b) that was similar to those with incidence (Fig. 3a). However, such correlations were stronger for winter residents than for summer visitors or summer residents, and not significant for winter visitors (Fig. 3b). Winter and summer visitors also showed narrower ranges of body sizes than residents species in two seasons, and all winter visitors were small bodied (Fig. 3b). 


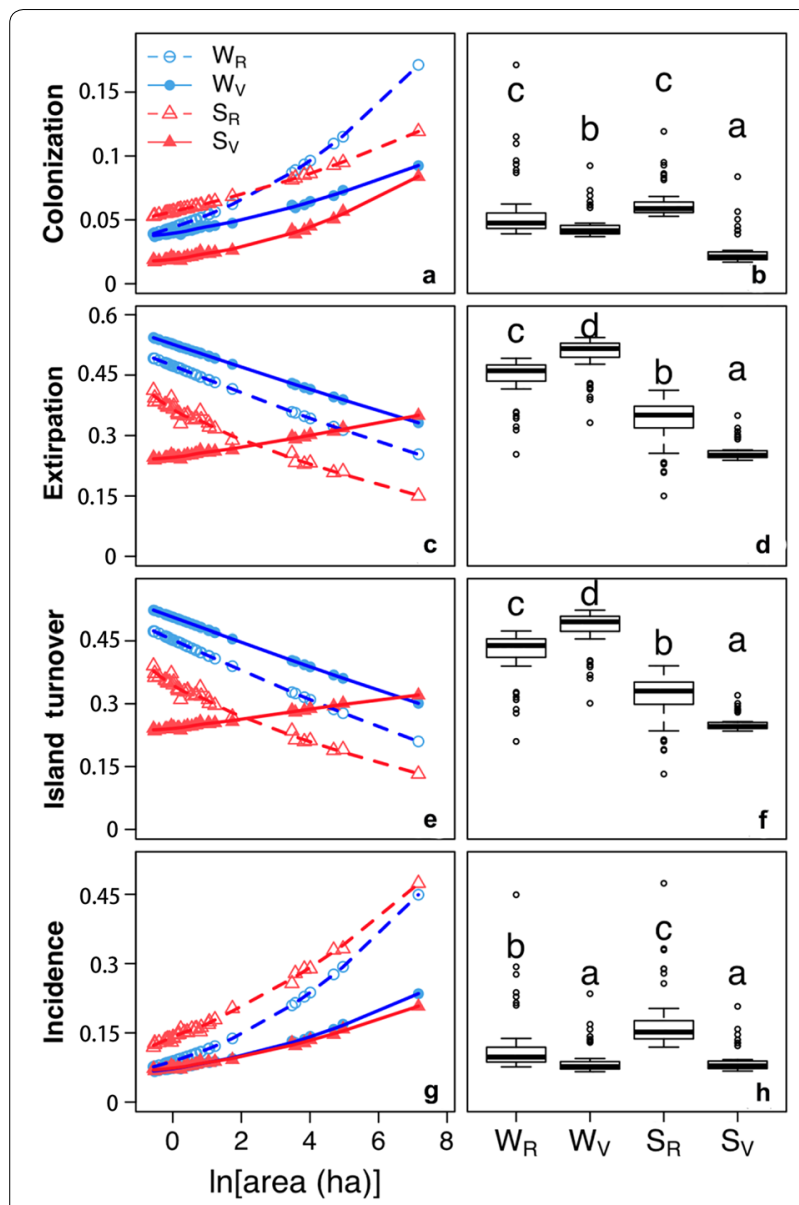

Fig. 2 The relationships between estimated island biogeography variables (left column) and island area for winter residents $\left(W_{R}\right)$, winter visitors $\left(W_{v}\right)$, summer residents $\left(S_{R}\right)$ and summer visitors $\left(S_{V}\right)$. The estimated colonization and extirpation rates in the right column were model-weighted averages, and other variables were derived from them (Full details in Additional file 2: Appendix). Bars beneath the same letter in the boxplots did not differ at $p<0.05$ in Tukey's HSD test. In box plots the thick bar represents the mean, the box represents the standard error, the error bar represents the 95\% confidence interval $(\mathrm{Cl})$, and points show more extreme values. The curves are loess fits at $p<0.05$

\section{Results of RLQ and fourth-corner analyses}

The ordinations used in RLQ explained a high proportion of variation in occupancy, island characteristics and species characteristics. Most of this variation was due to axis $1(88-99 \%)$ with little gain from exploring axis 2 results (Additional file 3: Table S6). For all bird assemblage types, occupancy was negatively related to habitat specificity and vertical specificity, and strongly positively related to area and habitat richness in RLQ axis 1 (Fig. 4a, Additional file 3: Fig. S1). The area results accorded with

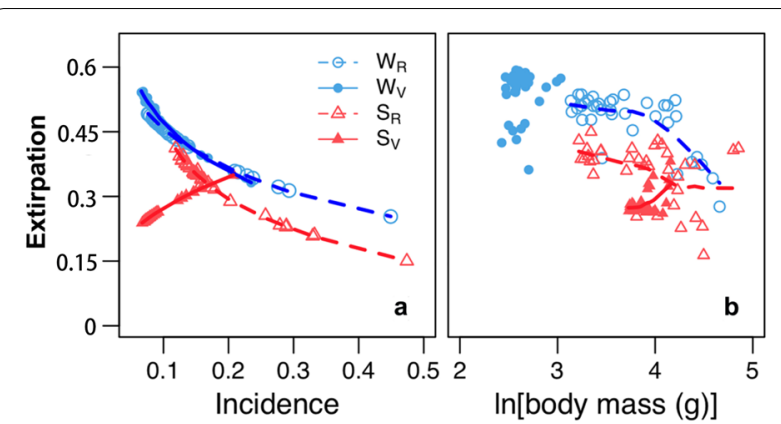

Fig. 3 The relationships between extirpation rates and incidence or average body mass of winter residents $\left(W_{R}\right)$, winter visitors $\left(W_{V}\right)$, summer residents $\left(S_{R}\right)$ and summer visitors $\left(S_{V}\right)$. The extirpation $(\mu)$ rates were model-weight averages, and incidence (an index of species richness) was the probability of presence of species on islands as described in Additional file 2: Appendix. The average body mass per island was the average species body mass per island weighted by occupancy frequency, as described in the Methods. The curves are loess fits at $p<0.05$

those of the previous section for incidence (Fig. 2g). Larger islands contain more diverse habitat types and a better-developed understory in taller and more extensive areas of forest. Consequently, there were more substratum birds and somewhat more habitat specialists on large habitat-rich islands than small islands with low habitat diversity. For summer or winter visitor species, occupancy was also strongly positively correlated with species' movement capacity, which accords with Hypothesis 2 (Fig. 4a). Body mass showed a weak positive correlation with area and habitat richness for residents and summer visitors, but the opposite for winter visitors (Fig. 4a). Consequently, large and habitat-rich islands contained more large species compared to small islands for all assemblages except winter visitors. By contrast, both buffer isolation $(B I)$ and distance to mainland $(D I)$ measures had minor effects on occupancy frequency (Fig. 4a).

Fourth-corner analysis showed significant relationships between occupancy frequency and island characteristics for all bird assemblages (Model 2, $p<0.001$ ). The associations between occupancy and species traits were significant for winter and summer residents (Model 4, both $p<0.001$ ), but not for summer or winter visitors (Model $4, p>0.1$ ). For residents in both seasons the results for area, habitat richness and vertical specificity resembled those in the RLQ analysis (Fig. 4). Like in the RLQ analysis, habitat specificity was correlated with area and habitat richness for summer residents, but this pattern was not significant for winter residents (Fig. 4b). Overall, 


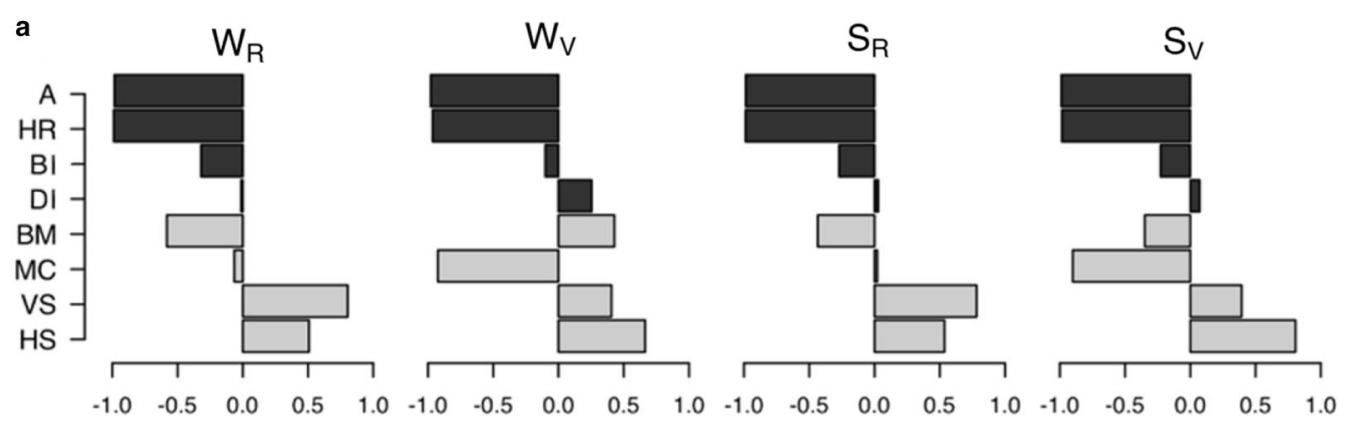

RLQ Axis 1 Standardized eigenvectors

b

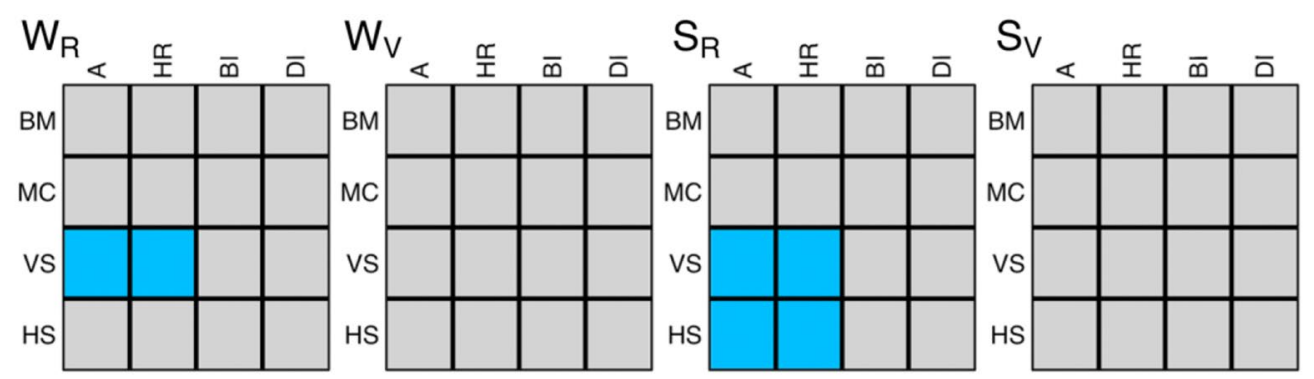

Fourth-corner analysis

Fig. 4 RLQ and fourth-corner analyses showing a standardized eigenvectors relating species ecological traits (grey bars) and island characteristic variables (black bars) along RLQ axis 1 (describing occupancy frequency), and $\mathbf{b}$ the bivariate relationships between island attributes and species ecological traits for winter residents $\left(W_{R}\right)$, winter visitors $\left(W_{V}\right)$, summer residents $\left(S_{R}\right)$ and summer visitors $\left(S_{V}\right)$. A area, HR habitat richness, $B$ l buffer isolation, D/ distance to mainland, BM body mass, MC movement capacity, VS vertical specificity, HS habitat specificity. Negative scores along the axis 1 in section are present positive associations between occupancy frequency and ecological traits as well as island characteristic variables. Blue cells in section b represent significant $(p<0.05)$ negative associations and gray cells were non-significant

these results show mixed results relative to the predictions of Hypothesis 4.

\section{Discussion}

By combing dynamic (e.g. temporal extirpation rates) and static views (RLQ analysis) of metacommunities, our study revealed strong seasonal differences in bird metacommunities. Overall, the turnover rates were lower for summer residents than for winter residents, and both assemblages showed strong associations with habitat vertical specificity. By contrast, winter and summer visitors showed non-significant associations with vertical habitat structure, and appeared to have low competitive ability relative to residents. A pattern existed where body size, migratory versus resident habitat and vertical habitat specificity were associated with the amount of extirpation and turnover in island land-bird assemblages (Table 1). This also corresponded to differences in idealized types of metacommunity dynamics but with a number of modifications, such as the role of species interactions in each season.
Consistent with Hypothesis 1, we found that winter residents and visitors had higher extirpation rates than breeding bird assemblages (Fig. 2d). In addition, observed extirpation (or evacuation) rates of wintering species were also disproportionately high on small islands (Fig. 2c). This matches empirical observations from the literature in several ways. First, unlike central-place foraging of breeding birds, winter birds are generally high mobile and use a wide range of habitats (Herrera 1978; Murgui 2007). Moreover, the high extirpation (or evacuation) probabilities of wintering species may also reflect low resource diversity in winter and limited buffering against severe winter conditions, especially on small islands (Wiens 1992; Murcia 1995; Nour et al. 2010).

Hypothesis 2 predicted that the high mobility of winter birds and especially winter visitors would increase their colonization rate relative to summer bird assemblages (Murgui 2007). Instead, colonization was significantly higher for residents than for visitors (Fig. 2b). This result is likely due to the low incidence of visitors (Fig. 2h), which potentially limits colonization (small species pool) compared to resident assemblages. Furthermore, the 
traits of resident species showed strong relationships with their habitat requirements (Fig. 4, rejecting Hypothesis 2). This corroborates the general view of the importance of year-round resource requirements for residents (Alatalo et al. 1987; Tellería and Santos 1997) and strong habitat selection by birds during breeding (Klingbeil and Willig 2016). As expected by Hypothesis 3, the overall turnover of bird assemblages was higher for winter than summer bird assemblages.

\section{Synthesis of seasonal variation in metacommunity paradigms}

The combination of colonizations, extirpation and RLQ analyses gives a holistic view of how the metacommunities differ across seasons and in seasonal visitor versus resident assemblages. Matching Hypothesis 4 there was also a strong correspondence between species traits, island attributes, extirpation-colonization dynamics, community composition and some correspondence to metacommunity paradigms.

Winter visitors were distinct from other assemblages, with high extirpation and intermediate colonization rates creating high turnover (consistent with Hypotheses 1 and 3 ). For winter visitors, a likely explanation is their small observed body sizes. Small-bodied species are assumed to have strong population fluctuations with high variation in birth and death rates (Pimm 1991; Cook and Hanski 1995). In particular, non-breeding winter visitors may be especially prone to extirpation during winter periods of extreme weather and resource shortage (Wiens 1992; Murcia 1995; Nour et al. 2010). This could have created high turnover and weak relations to islands characteristics (see also Hanski 1986; Peltonen and Hanski 1991). We also found that winter visitors had no habitat associations or species characteristics that clearly correlated with either occupancy (Fig. 4) or extirpation (Fig. 3b). This suggests that habitat-linked species sorting or mass effects are not likely. In non-breeding seasons, land birds are known to compensate for low resource availability (especially in winter) by increasing their mobility and breadth of habitat use (Wiens 1992; Murgui 2007, 2010; Klingbeil and Willig 2016). Both this and carryover effects from where birds spend the rest of the year outside of our study region may have caused weak habitat associations in our study (Marra et al. 1998; Norris and Marra 2007). Having inferred that mass effects and species sorting are not relevant, we conclude that winter visitor assemblages correspond to patch dynamics, neutral dynamics, or a spatially extensive well-mixed assemblage.

Summer visitors showed the lowest extirpation and island turnover of any assemblage (Fig. 2d, f), and low colonization rates (Fig. 2b). In addition, functional traits were weakly linked with species occupancy or island characteristics (Fig. 4). In the RLQ analysis, limited trait variations may weaken the eigenvalues representing the trait contributions. Similarly, we found that summer visitors had limited variation in body size (Fig. 3b) and were more frequently canopy dwellers than other assemblages ( $75 \%$ vs. $17-29 \%$ of other assemblages; Additional file 1: Table S3). This also accords with the view that summer visitors often forage higher and in more peripheral parts of vegetation than residents (Leisler 1992). Unlike other bird assemblages, average extirpation rates of summer visitors increased with island area, species richness (incidence) and average body size (Figs. 2c, 3a, b). Therefore, there is potential that negative species interactions, such as competition, occurred in breeding habitats. In our study, summer visitors overlapped in their ranges of body size with summer residents (Fig. 3b), which is consistent with patterns identified in European birds (Herrera 1978). Conversely, divergence in body size has been associated with the occupation of distinct niche space and the avoidance of interspecific competition (Brown and Wilson 1956; Bolnick et al. 2011). Hence, compared to summer residents, summer visitors may be competitively inferior, which is consistent with the positive effects of species richness on extirpation (Fig. 3a) and turnover, and could potentially drive the opposite effects of body size on extirpation and turnover compared to resident species (Fig. 3b). Overall, patterns for summer visitors best match either mass effects or species sorting. Higher extirpation rates on large speciose islands were inferred to be due to competition or other negative species interactions. Low turnover (Fig. 2e, f; as predicted by Hypothesis 3) makes mass effects less likely than species sorting since low movement while breeding might reduce extirpation.

Winter residents showed high extirpation rates (31\% per year), colonization and turnover (Fig. 2b, d, f; confirming Hypotheses 1-3), and strong associations between occupancy and vertical specificity (Fig. 4). Vertical specificity has frequently been used as a measure of habitat specialization for bird communities (Rayner et al. 2014), and habitat specialist or substratum species are expected to be especially sensitive to habitat fragmentation (Henle et al. 2004). The patterns we observed are most consistent with a mix of species sorting and patch dynamics. Mass effects are counter-indicated by the high extirpation, colonization and turnover. We predicted patch dynamics and not species sorting because we expected winter birds to have few habitat associations due to their expected high mobility (Murgui 2010), and associated need to increase breadth of habitat/resource use (Wiens 1992). The sedentary habits of resident birds were something we had not accounted for, but are reported in the literature (Nice 1941). 
Summer residents showed low extirpation (Fig. 2d, confirming Hypothesis 1), and the highest colonization rates of all assemblages (Fig. 2b, rejecting Hypothesis 2). This resulted in low species (island) turnover (Fig. 2f), as predicted by Hypothesis 3 based on high habitat specificity of breeding birds (White and Hurlbert 2010; Özkan et al. 2013). Habitat specificity potentially creates niche separation and reduces exclusion due to species interactions (cf. summer visitors in Fig. 3a). We found associations between occupancy and habitat factors (habitat and vertical specificity; Fig. 4). These findings conform to our prediction of species sorting for summer residents, although mass effects are also possible given the low observed turnover.

Our findings for three of the four assemblage types examined align with the existing empirical evidence that species sorting and mass effects are the most common metacommunity types (Cottenie 2005; Meynard and Quinn 2008; Logue et al. 2011), and that frequently systems show a mix of types of metacommunity dynamics (Logue et al. 2011).

\section{Conclusions}

Combining dynamic and static analyses of communities enhanced the insights obtained into metacommunities. Analyzing extirpation and colonization of species helped to characterize metacommunity processes, and it has not previously been shown that seasonal and migratory status can lead to different metacommunity dynamics (Driscoll and Lindenmayer 2009). Including species richness is also a likely indicator of the role of species interactions within local communities. While extirpation rates of residents were determined by island size (Chen et al. 2018a), for summer visitors extirpation was correlated with species richness rather than area. Such extirpation may be a driver of species sorting, and may therefore be driven by area or species richness depending on the bird assemblage under consideration.

\section{Additional files}

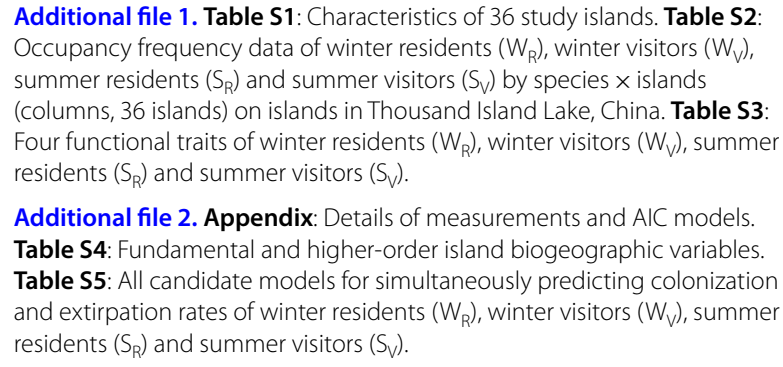

Additional file 2. Appendix: Details of measurements and AIC models. Table S4: Fundamental and higher-order island biogeographic variables. Table S5: All candidate models for simultaneously predicting colonization and extirpation rates of winter residents $\left(W_{R}\right)$, winter visitors $\left(W_{\mathrm{v}}\right)$, summer residents $\left(S_{R}\right)$ and summer visitors $\left(S_{V}\right)$.

Additional file 3. Table S6: Results of RLQ analysis using island characteristics and species ecological traits for winter residents $\left(W_{R}\right)$, winter visitors $\left(W_{V}\right)$, summer residents $\left(S_{R}\right)$ and summer visitors $\left(S_{V}\right)$. Figure $S 1$ : RLQ results relating species ecological traits and island characteristic variables along RLQ axes 1 and 2 for winter residents $\left(W_{R}\right)$, winter visitors $\left(W_{V}\right)$, summer residents $\left(S_{R}\right)$ and summer visitors $\left(S_{V}\right)$.

\section{Acknowledgements}

Not applicable.

\section{Authors' contributions}

All conceived the study. CC, YW, XS and PD collected the data. CC and MH performed the analyses and wrote the first draft of the paper. YW, XS and PD contributed to the writing of the manuscript. All authors read and approved the final manuscript.

\section{Funding}

This study was supported by National Natural Science Foundation of China (Grants 31210103908 and 31572250 to PD, Grant 31500453 to XS, Grants 31471981 and 31770462 to YW), and Jiangsu Postdoctoral Research Foundation (2018K169C) to CC. MH was supported by Agricultural Experiment Station to the University of California at Davis.

\section{Availability of data and materials}

All data generated or analyzed during this study are included in this published article [and its supplementary information files] and also available from the Pangaea database: https://doi.pangaea.de/10.1594/PANGAEA.885964.

Ethics approval and consent to participate Not applicable.

Consent for publication

Not applicable.

\section{Competing interests}

The authors declare that they have no competing interests.

\section{Author details}

${ }^{1}$ College of Life Sciences, Zhejiang University, Hangzhou 310020, China. 2 Jiangsu Key Laboratory for Biodiversity and Biotechnology, College of Life Sciences, Nanjing Normal University, Nanjing 210046, China. ${ }^{3}$ Department of Environmental Science and Policy, University of California, Davis, CA 95616, USA. ${ }^{4}$ School of Ecological and Environmental Sciences, East China Normal University, Shanghai 200241, China.

Received: 22 March 2019 Accepted: 14 June 2019 Published online: 20 June 2019

\section{References}

Alatalo RV, Eriksson D, Gustafsson L, Larsson K. Exploitation competition influences the use of foraging sites by tits: experimental evidence. Ecology. 1987;68:284-90.

Amarasekare P, Hoopes MF, Mouquet N, Holyoak M. Mechanisms of coexistence in competitive metacommunities. Am Nat. 2004;164:310-26.

Barbaro L, van Halder I. Linking bird, carabid beetle and butterfly life-history traits to habitat fragmentation in mosaic landscapes. Ecography. 2009:32:321-33.

Beven G. Changes in breeding bird populations of an oak-wood on Bookham Common, Surrey, over twenty-seven years. Lond Nat. 1976;55:23-42.

Bibby CJ, Burgess ND, Hill DA, Mustoe S. Bird census techniques. Amsterdam: Elsevier; 2000.

Bolnick DI, Amarasekare P, Araújo MS, Bürger R, Levine JM, Novak M, Rudolf VHW, Schreiber SJ, Urban MC, Vasseur DA. Why intraspecific trait variation matters in community ecology. Trends Ecol Evol. 2011;26:183-92.

Brook BW, Buettel JC. Emigration is costly, but immigration has benefits in human-altered landscapes. Funct Ecol. 2016;30:1478-9. 
Brown JH, Kodric-Brown A. Turnover rates in insular biogeography: effect of immigration on extinction. Ecology. 1977;58:445-9.

Brown WL, Wilson EO. Character displacement. Syst Zool. 1956;5:49-64.

Brown BL, Sokol ER, Skelton J, Tornwall B. Making sense of metacommunities: dispelling the mythology of a metacommunity typology. Oecologia. 2017;183:643-52.

Burnham KP, Anderson DR. Model selection and multimodel inference: a practical information-theoretic approach. New York: Springer; 2003.

Chave J. Neutral theory and community ecology. Ecol Lett. 2004;7:241-53.

Chen C, Holyoak M, Si X, Wang Y, Ding P. Do seasonal species assemblages differ in their biogeography? Evidence from the spatial structure of bird communities on land-bridge islands. J Biogeogr. 2018a;45:473-83.

Chen C, Holyoak M, Si X, Wang Y, Ding P. Species traits, habitat characteristics and spatial dynamics of birds on land-bridge islands. China: Thousand Island Lake. Pangaea; 2018b. https://doi.org/10.1594/PANGAEA.885964.

Cook RR, Hanski I. On expected lifetimes of small-bodied and large-bodied species of birds on islands. Am Nat. 1995;145:307-15.

Core Team R. R: a language and environment for statistical computing. Vienna: R Foundation for Statistical Computing; 2018.

Cottenie K. Integrating environmental and spatial processes in ecological community dynamics. Ecol Lett. 2005;8:1175-82.

Dolédec S, Chessel D, ter Braak CJF, Champely S. Matching species traits to environmental variables: a new three-table ordination method. Environ Ecol Stat. 1996;3:143-66.

Dray S, Dufour AB. The ade4 package: implementing the duality diagram for ecologists. J Stat Softw. 2007;22:1-20.

Dray S, Choler P, Dolédec S, Peres-Neto PR, Thuiller W, Pavoine S, ter Braak CJF. Combining the fourth-corner and the RLQ methods for assessing trait responses to environmental variation. Ecology. 2014;95:14-21.

Driscoll DA, Lindenmayer DB. Empirical tests of metacommunity theory using an isolation gradient. Ecol Monogr. 2009;79:485-501.

Ellis AM, Lounibos LP, Holyoak M. Evaluating the long-term metacommunity dynamics of tree hole mosquitoes. Ecology. 2006;87:2582-90.

Farneda FZ, Rocha R, López-Baucells A, Groenenberg M, Silva I, Palmeirim JM, Bobrowiec PED, Meyer CFJ. Trait-related responses to habitat fragmentation in Amazonian bats. J Appl Ecol. 2015;52:1381-91.

Fattorini $\mathrm{S}$. The influence of geographical and ecological factors on island beta diversity patterns. J Biogeogr. 2010;37:1061-70.

Fischer J, Lindenmayer DB. Nestedness in fragmented landscapes: a case study on birds, arboreal marsupials and lizards. J Biogeogr. 2005;32:1737-50.

Fukami T. Historical contingency in community assembly: integrating niches, species pools, and priority effects. Annu Rev Ecol Evol Syst. 2015;46:1-23.

Hanski I. Population dynamics of shrews on small islands accord with the equilibrium model. Biol J Linn Soc. 1986;28:23-36.

Henle K, Davies KF, Kleyer M, Margules C, Settele J. Predictors of species sensitivity to fragmentation. Biodivers Conserv. 2004;13:207-51.

Herrera CM. Ecological correlates of residence and non-residence in a mediterranean passerine bird community. J Anim Ecol. 1978;47:871-90.

Holyoak M, Leibold MA, Holt RD. Metacommunities. Chicago: University of Chicago Press; 2005.

Hubbell SP. The unified neutral theory of species abundance and diversity. Princeton: Princeton University Press; 2001.

Hutto RL. Habitat selection by nonbreeding, migratory land birds. In: Cody ML, editor. Habitat selection in birds. London: Academic Press; 1985. p. 455-73.

Klingbeil BT, Willig MR. Community assembly in temperate forest birds: habitat filtering, interspecific interactions and priority effects. Evol Ecol. 2016:30:703-22.

Leck CF. Seasonal changes in feeding pressures of fruit- and nectar-eating birds in Panama. Condor. 1972;74:54-60.

Legendre P, Galzin R, Harmelin-Vivien ML. Relating behavior to habitat: solutions to the fourth-corner problem. Ecology. 1997;78:547-62.

Leibold MA, Chase JM. Metacommunity ecology. Princeton: Princeton University Press; 2017.

Leibold MA, Holyoak M, Mouquet N, Amarasekare P, Chase JM, Hoopes MF, Holt RD, Shurin JB, Law R, Tilman D, Loreau M, Gonzalez A. The metacommunity concept: a framework for multi-scale community ecology. Ecol Lett. 2004;7:601-13.

Leisler B. Habitat selection and coexistence of migrants and Afrotropical residents. Ibis. 1992;134:77-82.
Levey DJ, Stiles FG. Evolutionary precursors of long-distance migration: resource availability and movement patterns in neotropical landbirds. Am Nat. 1992;140:447-76.

Logue JB, Mouquet N, Peter H, Hillebrand H. The metacommunity working group. Empirical approaches to metacommunities: a review and comparison with theory. Trends Ecol Evol. 2011;26:482-91.

MacKenzie DI, Nichols JD, Seamans ME, Gutiérrez RJ. Modeling species occurrence dynamics with multiple states and imperfect detection. Ecology. 2009:90:823-35.

MacKinnon JR, MacKinnon J, Phillipps K, He FQ. A field guide to the birds of China. Oxford: Oxford University Press; 2000.

Marra PP, Hobson KA, Holmes RT. Linking winter and summer events in a migratory bird by using stable-carbon isotopes. Science. 1998;282:1884-6.

Meynard CN, Quinn JF. Bird metacommunities in temperate South American forest: vegetation structure, area, and climate effects. Ecology. 2008;89:981-90.

Murcia C. Edge effects in fragmented forests: implications for conservation. Trends Ecol Evol. 1995;10:58-62.

Murgui E. Effects of seasonality on the species-area relationship: a case study with birds in urban parks. Glob Ecol Biogeogr. 2007;16:319-29.

Murgui E. Seasonality and nestedness of bird communities in urban parks in Valencia, Spain. Ecography. 2010;33:979-84.

Nice MM. The role of territory in bird life. Am Midl Nat. 1941;26:441-87.

Norris DR, Marra PP. Seasonal interactions, habitat quality, and population dynamics in migratory birds. Condor. 2007;109:535-47.

Nour N, van Damme R, Matthysen E, Dhondt AA. Forest birds in forest fragments: are fragmentation effects independent of season? Bird Study. 2010;46:279-88.

Özkan K, Svenning JC, Jeppesen E. Environmental species sorting dominates forest-bird community assembly across scales. J Anim Ecol. 2013;82:266-74.

Pavoine S, Baguette M, Stevens VM, Leibold MA, Turlure C, Bonsall MB. Life history traits, but not phylogeny, drive compositional patterns in a butterfly metacommunity. Ecology. 2014;95:3304-13.

Peltonen A, Hanski I. Patterns of island occupancy explained by colonization and extinction rates in shrews. Ecology. 1991;72:1698-708.

Pimm SL. The balance of nature? Ecological issues in the conservation of species and communities. Chicago: University of Chicago Press; 1991.

Rayner L, Lindenmayer DB, Wood JT, Gibbons P, Manning AD. Are protected areas maintaining bird diversity? Ecography. 2014;37:43-53.

Russell GJ, Diamond JM, Reed TM, Pimm SL. Breeding birds on small islands: island biogeography or optimal foraging? J Anim Ecol. 2006;75:324-39.

Schoener TW. Sizes of feeding territories among birds. Ecology. 1968:49:123-41.

Schoereder JH, Galbiati C, Ribas CR, Sobrinho TG, Sperber CF, DeSouza O, Lopes-Andrade C. Should we use proportional sampling for species-area studies? J Biogeogr. 2004;31:1219-26.

Si X, Pimm SL, Russell GJ, Ding P. Turnover of breeding bird communities on islands in an inundated lake. J Biogeogr. 2014;41:2283-92.

Si X, Cadotte MW, Zeng D, Baselga A, Zhao Y, Li J, Wu Y, Wang S, Ding P. Functional and phylogenetic structure of island bird communities. J Anim Ecol. 2017:86:532-42.

Song X, Holt RD, Si X, Christman MC, Ding P. When the species-time-area relationship meets island biogeography: diversity patterns of avian communities over time and space in a subtropical archipelago. J Biogeogr. 2018:45:664-75.

Stracey CM, Pimm SL. Testing island biogeography theory with visitation rates of birds to British islands. J Biogeogr. 2009;36:1532-9.

Tellería JL, Santos T. Seasonal and interannual occupation of a forest archipelago by insectivorous passerines. Oikos. 1997;78:239-48.

Tramer EJ. Proportions of wintering North American birds in disturbed and undisturbed dry tropical habitats. Condor. 1974;76:460-4.

Wang Y, Bao Y, Yu M, Xu G, Ding P. Nestedness for different reasons: the distributions of birds, lizards and small mammals on islands of an inundated lake. Divers Distrib. 2010;16:862-73.

Wang Y, Chen S, Ding P. Testing multiple assembly rule models in avian communities on islands of an inundated lake, Zhejiang Province, China. J Biogeogr. 2011;38:1330-44. 
Wang Y, Thornton DH, Ge D, Wang S, Ding P. Ecological correlates of vulnerability to fragmentation in forest birds on inundated subtropical land-bridge islands. Biol Conserv. 2015;191:251-7.

White EP, Hurlbert AH. The combined influence of the local environment and regional enrichment on bird species richness. Am Nat. 2010;175:E35-43.

Wiens JA. The ecology of bird communities. Cambridge: Cambridge University Press; 1992.
Zhuge Y. Fauna of Zhejiang: aves. Zhejiang: Zhejiang Science and Technology Publishing House; 1990.

Zuckerberg B, Fink D, La Sorte FA, Hochachka WM, Kelling S. Novel seasonal land cover associations for eastern North American forest birds identified through dynamic species distribution modelling. Divers Distrib. 2016;22:717-30.
Ready to submit your research? Choose BMC and benefit from:

- fast, convenient online submission

- thorough peer review by experienced researchers in your field

- rapid publication on acceptance

- support for research data, including large and complex data types

- gold Open Access which fosters wider collaboration and increased citations

- maximum visibility for your research: over $100 \mathrm{M}$ website views per year

At BMC, research is always in progress.

Learn more biomedcentral.com/submissions 